\title{
Smart Community and Social Resilience: Reflection on the COVID-19 Pandemic
}

\author{
Calvin M.L. CHAN \\ Singapore University of Social \\ Sciences \\ calvinchanml@suss.edu.sg
}

\author{
Dong QIU \\ Fujian University of Technology \\ qd613@qq.com
}

\author{
Felix T.C. TAN \\ University of New South Wales \\ f.tan@unsw.edu.au
}

\begin{abstract}
This paper presents a study on how smart community in Singapore functioned to generate social resilience during the COVID-19 pandemic. As conventional community can no longer function amid social distancing and lockdown regulation, smart community began to fill the void that is left behind. The study demonstrated how smart community generated each of the six attributes of social resilience, which has great relevance given the disruption and distress brought about by the pandemic. The analysis revealed how smart community can function to not only maintain but also enhance social resilience. Implications of this study is then presented, with greater emphasis given to future research direction given the embryonic state of this research area. Considering the increasing need for smart community in the new normal of a post COVID19 world, further research into how smart community may contribute to the social resilience of the community will be needed.
\end{abstract}

\section{Introduction}

The recent COVID-19 pandemic brought about tremendous disruption to economic as well as social activities. As cities and countries around the world entered into shutdown mode, trade and commerce in brick-and-mortar shops are halted. Work in offices and learning in schools are also terminated. Even social gathering across different households are prohibited. All these are done as part of social distancing measures to slowdown the spread of the virus so that stretched healthcare services can have a better chance in coping with rapidly escalating number of infected people.

Yet, through digital enablement brought about by the use of digital technology, trade and commerce continued to take place online through e-commerce platforms $[1,2]$. Work and learning are able to happen from home through remote telecommuting, online conferencing platforms and e-learning arrangement [3, 4]. Social connection are maintained through the use of social media, online conferencing and video calls. The ubiquitous use of digital technology in many cities and countries thus brought some degree of reprieve to what might have been more dire economic and social consequence of the pandemic $[5,6]$.

Further, it is observed that the use of digital technology by communities in responding to the COVID-19 pandemic also helped to enhance social resilience and enabled the community to better deal with the impact of the pandemic. This paper shows that the development of smart community, with digital technology used pervasively, could maintain and even enhance the social resilience of the community.

The organization of this paper is as follows: the next section presents the concept and development of smart community. This is followed by a review on social resilience, focusing on the six attributes of social resilience proposed by McLean et al. [24]. The research design is then presented. Illustrative examples from Singapore, which was among the first countries in the world to face the onslaught of the pandemic but yet experienced one of the lowest fatality rate (at less than one percent as of early July 2020), are then presented to demonstrate how smart community can maintain and even enhance social resilience. Before drawing the paper to a conclusion, a discussion on the implication to the development of smart community, with emphasis given to future research direction as this area of research is still in its early stage of development.

\section{Smart community}

While attracting increasing attention, the 'smart community' concept remains to be emerging and nebulous [7, 8]. Interest in this concept lies in the recognition that the usage of various digital technologies, such as artificial intelligence, internet-ofthings, blockchains and analytics, can augment and advance the development and wellbeing of communities living in major cities, urban or rural towns or even remote villages. This may be in the form of enabling and 
empowering individuals through the use of digital technologies [7, 9], or the cultivation of collective and communal good such as social capital and environmental sustainability $[10,11,12,13]$. Interestingly, while digital technology is able to support the formation of purely virtual/online community [14, 15], a number of studies indicated that geographical proximity actually enhances the functioning of smart community $[9,10,16]$. This is arguably a key differentiation between the concepts of 'smart community' and 'virtual/online community'. The concept of 'smart community' is associated with the development of 'smart city' [7, 9, 11] where digital technology, especially internet-of-things technology, are used to enhance the municipal functioning of cities, towns or villages. The concept of 'smart community' is thus entwined to these geographically bounded cities, towns or villages, but instead of focusing on municipality of the cities, towns or villages, research on 'smart community' focuses on the groups of individuals who lives in such smart city $[10,11,12]$. This contrast with the concept of 'virtual/online community', which are essentially social aggregation of individuals who interact in cyberspace over extended and durable duration to form mutual feelings and personal connection [15]. Examples of 'virtual/online community' include various social media groups such as those on Twitter, Facebook and Instagram, as well as online gaming groups [14, 15, 16, 17]. In comparison, the research on 'virtual/online community' is considerably more defined and established than 'smart community'.

As with the studies of most nascent and contemporary phenomenon, the literature on smart community is rather fragmented and cuts across silos of conventional disciplines such as information systems [8, 12, 18], e-government [7, 10, 11, 12, 19] and urban planning $[13,20,21]$. Considering such diversity, it is unsurprising that a multitude of investigative approaches as well as research focus are evidenced from the literature.

In this paper, the focus is on how the use of digital technology help to enhance the social resilience of communities during the COVID-19 pandemic.

\section{Social resilience}

Social resilience is an important attribute of any functioning community. Resilience can be understood as the ability to withstand, cope, and manage external shocks and disruptions [22, 23]. Social resilience relate to how communities withstand, respond, and recover from external shocks and disruptions either collectively or individually [24, 25]. These external shocks and disruptions can manifest in different forms such as natural or man-made disasters to the ecological, geopolitical, economic or social systems.

While it has been raised that there is conceptual overlap between social resilience and adaptive capacity $[24,25]$, the latter is more generic in that it is centered simply on the ability to adapt with little regards to how the ability is developed, or to the actors or agents involved. Put it this way, adaptive capacity can be possessed by an individual, a group of people, or even an organization/institution. In contrast, social resilience focuses on the processes, and the actors or agents are always either the collective community or individuals living in the community [24].

Further, adaptive capacity only captures one aspect of social resilience as an individual, groups or organization/institution ability to learn and selforganize in face of shocks and disruptions from the environment [24]. Social resilience also encompass another aspect whereby the focus is on developing the capacity to withstand and cope with adversity brought about by the shocks and disruptions [26]. These two aspects are liken to two sides of a single coin.

Motivated to advance a more proactive, as oppose to reactive, approach to developing social resilience, Maclean et al. [24] identified six attributes of social resilience. These six attributes are (i) knowledge, skills and learning; (ii) community networks; (iii) peopleplace connection; (iv) community infrastructure, (v) diverse and innovative economy; (vi) engaged governance. Each of these attributes presents one approach or dimension through which social resilience can be proactively developed. As such a proactive approach aligns with the focus of this study to examine how smart community can generate social resilience amidst the COVID-19 pandemic, it is therefore employed as the guiding framework.

\subsection{Knowledge, skills and learning}

The attribute of knowledge, skills and learning in social resilience refers to the partners among individuals, groups and even institutions to cultivate knowledge, skills and learning in enhancing the community's capacity to cope, adapt and respond to the external shocks and disruptions. Often, such knowledge, skills and learning may have to be contextualized and adapted to fit local needs and situations. During times of crisis and emergency, having accurate and reliable information may be a matter of life-and-death. The complexity of such situations requires not only topdown dissemination of instructions and information, but also bottom-up information flow of the actual situation on the ground to develop more accurate situational awareness and improve planning of respond and rescue operation [27]. 


\subsection{Community network}

The attribute of community network is associated with the concept of social capital [28, 29], which can be understood loosely as the social processes and activities that are enacted through social relationships and social structures, generating supportive benefits to individuals and or groups in a community. It serves as a basis for the community to relate and engage for hope, support, camaraderie and even solidarity, especially in face of challenges brought about by external shocks and disruptions.

\subsection{People-place connection}

This attribute of people-place connection highlights the importance of human-environment connection and interdependencies. Communities often build their identity in relation to the place upon which the communities reside or conduct it activities. Such sense of identity serves as basis for strength, gumption and hope in enduring challenges and difficulties brought about by external shocks and disruptions. Along with the rise of digitalization, places may either be actual physical location or cyber spaces $[15,30]$.

\subsection{Community infrastructure}

Community infrastructure serves to facilitate and provides for the activities needed to support the community to face, cope, respond and recover from the external shocks and disruptions. These can be in the form of medical and humanitarian aids and services, community centers, social and recreational facilities, transportation amenities, or even cultural or religious services. Thus, community infrastructure provides the scaffolds through which the multi-facetted needs of the community can be fulfilled.

\subsection{Diverse and innovative economy}

This attribute focuses on the economic life of a community. Having a diverse and innovative economy enables the livelihood of the community to be sustained even in spite of the external shocks and disruptions. The emphasis on diversity is such that a more diverse economy enables a higher degree of fungibility and agility in adapting to changes. On the other hand, the emphasis on innovativeness acknowledges the need to develop new and novel approaches in adapting to changes.

\subsection{Engaged governance}

This attribute is about having a collaborative approach in place to facilitate decision making mechanism. It involves providing for stakeholders in and of the community to participate and be engaged in dealing with the external shocks and disruption. Often, when the situation is urgent, a highly consultative approach may not be possible, suitable nor ideal. Engaged governance is thus not about collective decision making, but about having mechanism that incorporates the thoughts and feelings of the community in the decision making. It is not just about the efficiency of the decision making, but more about the efficacy of the decision making in reflecting the needs, wants, and aspiration of the community in face of external shocks and disruption.

\section{Research approach}

The COVID-19 pandemic presented an opportunity to study how smart community can affect the social resilience of a community. The COVID-19 pandemic took the world by surprise even though many futurist and strategist have predicted the plausibility of a global pandemic. Many countries and community are caught off guard and ill-prepared for it even as it spread rapidly around the world at the beginning of 2020. Given the urgency of the situation and speed at which the virus spread, lockdown of cities, towns and villages was imposed, prohibiting social gathering and bringing much economic activities to a standstill, placing a strain on the social resilience of communities in these places.

This research is situated in Singapore which is among the first countries in the world with reported COVID-19 cases in January 2020. Although it is lauded as a 'gold standard' by epidemiologists in the early stages of its fight against the virus [31], the number of reported cases subsequently saw a sharp surge in March 2020 and has mostly remained in the hundreds on a daily basis due mainly to transmission in the dormitories of migrant workers. As of July 2020, there were 26 fatal cases out of more than 46,000 reported cases among its population of 5.7 million people. The pandemic has no doubt impacted the social resilience of the city-state.

Furthermore, Singapore is also an apposite site to study how smart community affects social resilience as it is ranked top in the IMD Smart City Index out of 102 cities worldwide [32].

The researchers have been making observation from January to early July 2020 on how various smart city initiatives in Singapore has impacted the social resilience of the community as the pandemic unfolded its impact. As the city-state went into a state of lockdown between April and June, it was not possible to 
conduct in-person interviews to collect first-hand data to corroborate the observation. As social activities ceased, it was also difficult to arrange for online interviews. Hence, the alternative of conducting online search of established news media outlet was adopted in seeking data to corroborate the observation. Online search were conducted via Google News and Yahoo News, as well as on the website of key established media, including both international outlets (e.g. CNN and BBC News) and local outlets (e.g. ChannelNewsAsia and The Straits Times). Concerns over subjectivity in the identification of relevant events and initiatives were mitigated in part as the reporting from these established media are deemed to be trustworthy as the events reported and interviews cited can all be verified and authenticated.

The six attributes of social resilience were adopted as theoretical sense making lens [33]. This approach of analysis is established for analyzing process data [34, 35], where events and initiatives that matches the theoretical sense making lens are selected to be featured. When more than one event or initiative matched with an attribute, only the event or initiative that most fittingly illustrate attribute is chosen to be featured.

\section{Smart community and social resilience during the COVID-19 pandemic}

Based on analysis of the situation in Singapore against Mclean et al.'s six attributes of social resilience [24], the following are how smart community is observed to have maintained or even enhanced social resilience during the COVID-19 pandemic.

\subsection{Knowledge, skills and learning}

During the onset of the COVID-19 pandemic, considerable incidents of fake news propagation occurred through the social media, either out of intentional malice or mischief, or out of ignorance or carelessness. Such propagation of misinformation has caused confusion, psychological stressed and mass hysterical anti-social behavior such as panic buying and hoarding of foodstuffs and household products such as toilet papers [36, 37]. For example, in Singapore, a man was actually found to have circulated fake news to urge people to stock up on their daily necessities as the government would close all coffee shops and food courts, and only allow supermarkets to be opened for two days every week [38]. Such misinformation can have negative impact on social resilience of the community as it erodes trust in the community and may even lead to animosity in the community as people scuffle over limited supplies available.
Like many governments around the world, the Singapore government not only relied on traditional media but also turned to social media to dispel such misinformation, by providing a source of reliable and verified information pertaining to the pandemic on popular social media platforms such as WhatsApp and Telegram. Those interested can subscribe to these platforms to receive regular and timely information releases through these social media platforms so as to stub out the propagation of fake news [39].

Thus, smart community utilized social media to combat fake news and misinformation, thereby enhancing social resilience during the pandemic.

\subsection{Community network}

Being Asian with strong familial bonds and living on the small island city-state, most Singaporeans would organize social get-together with friends and extended families on weekends. Thus, the imposition of social distancing regulation and the prohibition of all social gatherings during the early phases of the lockdown terminated all family get-together and meet-up with friends. These led to social isolation and loneliness among seniors who live by themselves, and stress on young families who rely on grandparents to share in the caregiving of their young children $[40,41]$.

To cope with the situation, many turned to online digital platforms to keep some degree of the community network active. For instance, as Mothers' Day took place in the midst of the lockdown, many went online to order flowers and food as Mother's Day gifts [42, 43]. Others made use of video-conferencing platforms such as Zoom to host virtual family gathering [44].

Subsequently, after two months of stringent phase one lockdown, limited social gathering of not more than five persons in public places and not more than five visitors to households are permitted. This enabled community network to resume to a higher level. In order to ensure that another potential surge in the spread of the virus can be managed and contained, three different movement tracing digital solutions are rolled out. The first solution is known as SafeEntry, which is an app that requires visitors to public places, such as malls, restaurants and supermarkets, to check their temperature and to register their entry and exit by scanning a QR code [45]. There is also a variation of the SafeEntry app that is linked to a tablet that works as an infrared thermometer, camera, barcode scanner and near-field communication (NFC) reader that automatically takes the temperature and registers visitors by scanning their heads and having them scan the barcode on their national identity cards [46]. This latter variation allowed for a quicker and smoother human traffic flow and 
avoided the formation of crowds and queues for temperature taking and entry registration.

The second solution is the TraceTogether app which utilize the Bluetooth NFC sensor that is built into smartphones to sense other smartphones the TraceTogether app turned on in the vicinity [47]. The records are stored on the smartphones of the users for 21 days so that in the event that one of these smartphone users were to contract the virus, relevant contacts can be traced and contained.

The third solution is the TraceTogether Tokens, which works similarly as the TraceTogether app but come in the form of a token. The token is essentially targeted at the less technologically savvy senior citizens who do not use or are not adept in using smartphones [48].

As can be seen, despite the social distancing regulation and lockdown, different digital technologies enabled community network to be maintained to various degrees at different phases of the lockdown, and for different groups of the community.

\subsection{People-place connection}

Around the world, local communities are observed to express their support and appreciation for their healthcare and frontline workers through various means. Similar phenomenon occurred in Singapore as well, where thousands of people joined an island-wide singalong session to one of the island-state's favorite nationalistic song [49]. Extending beyond the shores of the island-states, more than nine hundred Singaporeans from all over the world was also assembled using digital technology into a video of 'virtual collage choir', which is broadcasted simultaneous on many radio stations, television stations and social media platforms in synchrony with the singalong session. Members of the community are also encouraged to submit video recording of their singalong, which was further assembled into another video collage and released a few hours later.

Those interviewed attested to how the event roused the morale of the community. For instance, the organizer of the 'virtual collage choir' shared that the event "provide(d) a platform for Singaporeans all over the world to unite through song......the gathering of voices to represent the unique gifts of diverse Singaporeans to build a pandemic-resilient nation through unity." [50]

Another organizer of the event also mentioned: "If every block and estate has voices ringing out, and social media goes nuts with everyone's uploaded videos, that would make every frontline worker realize that we love them for what they're doing." [51]
The general manager of one of the participating radio station also commented that the station is "proud to be part of this movement as we want to show our solidarity with fellow Singaporeans and our appreciation to our brave front-liners." [49]

A member of the community also shared that "I could hear many of my neighbors singing and my parents and siblings sang along too. It was really a boost for morale." [49]

Thus, digital technology is again utilized by the community to enhance social resilience, and specifically showcasing the people-place attribute in this instance.

\subsection{Community infrastructure}

With a rapidly ageing population, senior activity centers can be found across the island-state where seniors get together on a regular basis to engage in activities that cater to their mental, social as well as physiological wellbeing. During the pandemic, all senior activity centers are closed in view that the seniors are among the most vulnerable to the COVID-19 virus [52]. Notwithstanding the closing of the center, activities to engage the seniors shifted online through the use of digital technologies. For instance, activities that used to take place in the senior activity centers are consolidated and live-cast on social media. These includes morning exercise, cooking demonstration, health talks, and also guidance in going online and using digital technologies [53].

For senior who prefers to interact with people, some of the senior activity centers also partnered with corporations to conduct virtual befriender sessions for seniors in seeing to their emotional and mental health. A typical session will see a senior being paired with up to two employees from partnering corporation. Each group will interact for about an-hour via videoconferencing, where the senior will use tablet computers provided to them by the senior activity centers. As the chairman of a senior activity center shared: "This...program adds a bright spot to their day and gives them a sense of purpose as they embrace and adopt technology into their lives. We plan to continue to grow and expand the virtual befriending program even after the guidelines on social distancing are relaxed." [54]

Sensing concerns among the seniors over use of digital technologies, comprehensive programs are also progressively established to help seniors overcome the barrier to digital technology adoption. These include providing more affordable mobile subscription plans [55], and setting digital community hubs around the island where seniors can seek help and assistance is using digital technologies $[56,57]$.

Hence, digital technology enabled community infrastructure to continue functioning albeit that 
physical infrastructures remained shut due to the pandemic. Moreover, considering the additional measure put in place to help the seniors adopt digital technology, additional support for certain segment of the community may be needed in developing the smart community in an inclusive manner so as to not leave anyone left behind.

\subsection{Diverse and innovative economy}

The pandemic induced lockdown resulted in many non-essential shops and businesses to be shut. Moreover, while restaurant and eateries remained open, no dining-in is allowed, and only take-away option are available. In implementing social distancing regulation, crowd control is also put in place at markets and food centers. Even as shops are shut, business nimbly and innovatively switched to telecommuting work-fromhome arrangement for the employees and turned to online e-commerce to carry on trading as the infrastructure, e.g. high-bandwidth Internet, online payment infrastructure, are already in place [58, 59].

As sales slowed with the lockdown, some market stall owners experimented by hawking their produce through live-streaming sale events using Facebook Live. This proved popular with consumers as one of the stall owner revealed: "We actually planned for one hour (of) sales but it's now half an hour and we are sold out....I'm very happy and of course, I would do this again." [58]

The Facebook Live approach require orders to be placed by leaving comment on the Facebook Live stream. Stall owners will then reach out to the customers to confirm their orders and request for the customers to send in their contact number and delivery addresses via Facebook messenger. Payment can then be made using mobile payment channel and delivery charges may be waived for orders above a certain amount [60].

There are also other stall owners that experimented with other ordering approaches such as using WhatsApp messaging platform, Google spreadsheet, and also established e-commerce platforms. As most of the technical infrastructure are pre-existing, there is little technical challenges to set up such sales events. Another stall owner shared: "The biggest challenge I feel is not technical, but economical. How do we deliver our produce to customers but still do it at a profit after considering fulfilment and delivery costs?" [61]

Notwithstanding, it remained that not all small-andmedium-sized enterprises are technology savvy. As a Minister commented: "During the circuit breaker (lockdown), those that had e-solutions could still continue payments... Those that were on manual systems would have been stuck because they couldn't go back to the office" [62]. Determined to support the less technology savvy enterprises to embrace and take advantage of digital technology, the government has been trying to help these firms digitalize too. As another Minister revealed: "I think we will need to do more work, understand their concerns, address their fears and see how we can then get them to cross the Rubicon... We need to get onto that platform so this whole world of new opportunities is open to us, then we can let innovation and entrepreneurial energy take its course." [63]

Therefore, it can be seen that in a smart community, businesses that are more technology savvy are more ready to fulfill the diverse and innovative economy attribute of social resilience.

\subsection{Engaged governance}

Singapore's National Day is on the $9^{\text {th }}$ of August and planning for the nation-wide celebration has also been hampered by the pandemic. The day is usually marked by a large-scale parade and performance put up by thousands of participants, and a live audience into the tens of thousands.

With the pandemic not showing any signs of subsiding, there were some in the community who felt that the parade should be cancelled, while others argued to holding it in spite of the pandemic to drive up morale and rally Singaporeans together during these trying times [64, 65]. Considering the online chatters and feedback on traditional as well as social media, it was subsequently decided that the parade will still proceed but will be decentralized and on a smaller-scale [66]. To enable every citizen to be able to participate, every household will be given a bag of National Day paraphernalia.

This raised another round of complaints on the social media and even an online petition from some pockets of the community who felt that the bags of paraphernalia will just end up as environmentally-unfriendly junk and a waste of taxpayers' money, especially considering the economic impact of the pandemic [67, 68, 69].

In the end, the committee planning for the parade provided opt-out option for those who do not want the bag, with the government seeking further feedback on the issue with the community $[70,71,72]$.

Hence, technology such as social media and online petition facilitated engaged governance despite the lack of physical interaction due to pandemic.

\section{Discussion}

This study examined how smart community managed to develop social resilience during the COVID-19 pandemic basing on the experience of 
Singapore, which is ranked as a top smart city out of 102 cities [32].

Previous studies on smart communities have mainly focused on the development and formation of smart communities [ $8,9,10,11,12]$. In addition, there are also studies showing how digital technology can be useful, and even life-saving, in times of crisis and disaster [27, $73,74]$. This study thus adds to these corpus of works by studying how the use of digital technology have contributed to the functioning of a smart community during the crisis presented by the COVID-19 pandemic. In more precise terms, the above analysis illustrated how digital technology has contributed to the sustenance and even the enhancement of social resilience in a smart community during a time of crisis. This is shown through illustrating how each of the six attributes of social resilience were enabled by digital technology.

Even though research interest in resilience and social resilience has grown in recent years [22], the body of literature on social resilience in smart community is still embryonic, with only two studies being identified. The first study [74] explored the attitudes of European communities towards using social media in emergency situations, with attempts made to relate how social media enabled cooperation during emergency with a form of social resilience known as cooperative resilience, which is the ability to overcome crisis of cooperation by means of technology to adapt and modify realities. Arguably, cooperative resilience only aligns with the community network and community infrastructure attributes of social resilience covered in this study. The second study [75] examined the use of digital technology by smart community in rural Canada, and how such usage altered the social resilience of the community. The findings relate to the social resilience attributes of people-place connection, and diverse and innovative economy covered in this study. Thus, this study can be seen to present a comprehensive view of how smart community utilizes digital technology to generate social resilience across all six attributes.

In addition, previous studies on the use of digital technology by smart community in crisis and disaster response and recovery has largely centered on the use of social media $[27,73,74]$. While social media is still very much featured in this study, i.e. across all six attributes of social resilience, a richer variety of digital technologies are also featured, especially in the community network attribute. The digital technology featured includes solutions that leverage on internet-ofthings, analytics as well as artificial intelligence. This may be an indication of the progressive maturity and ubiquity of such technology such that they are now being used by smart community. Future research may thus examine the use of such more advanced digital technology in addition to the usual feature on social media and digital platforms [12, 27, 73]. Future research may also explore how such advanced digital technology may be utilized by smart community in developing social resilience.

Further, while social resilience is certainly crucial during times of emergency, crisis and disaster [74], smart community continues to function and exist even in normal, non-critical times. While this study and the early study [74] examined the development of social resilience in smart community during critical times such as the COVID-19 pandemic, there is currently a research gap on how smart community develop social resilience during normal times. May such development be similar as what have been found in this study, or may it take on drastically different form when there is an absence of urgency and criticality in the situation? It is argued that it may be better for smart community to cultivate social resilience during normal times so that when a crisis or emergency is to happen, the pre-existing social resilience of the smart community may then be tapped to support the smart community through when the situation turns harsh.

As this study focuses on how the use of digital technology helped to enhance the social resilience of communities during the COVID-19 pandemic, the analysis tends to be affirmative and positive. It is nonetheless acknowledged that the use of digital technology can be problematic and may generate adverse effects and concerns. For instance, even as digital technologies such as the TraceTogether app enabled community network to be maintained, concerns over privacy and security still exist. Although the government has assured the public that the app only captures and stores data on the users' smartphones and will only be downloaded when contact tracing is required, there are still some who refused to use the app. Future studies can thus present more comprehensive analysis by covering positive aspects of how digital technology helped to enhance social resilience as well as any associated negative aspects and unresolved challenges.

These may all be areas to be explored in future research.

\section{Conclusion}

The COVID-19 pandemic has brought about much disruption to community life for many people around the world. Many communities went into a standstill as social activities drew to a halt due to social distancing and lockdown regulations. Under such circumstance, the value and importance of smart community is accentuated as it may be the only form of community life that remains functional in spite of the mayhem brought about by the pandemic. Furthermore, if not well 
directed, smart community may also turn against its own wellbeing as social media can be used to propagate misinformation or generate psychological stress and mass hysterical anti-social behavior in the community. This study demonstrated how smart community can function in a way that generated social resilience during the pandemic, thereby facilitating the community to better deal with and respond to it. Notwithstanding, research on social resilience in smart community is still nascent and further research will be needed so that more communities around the world can leverage on digital technologies in not only transforming themselves into smart communities, but also to build up the social resilience of the community in preparing for the new normal in a post COVID-19 world.

\section{References}

[1] Kim, R. Y., "The Impact of COVID-19 on Consumers: Preparing for Digital Sales", IEEE Engineering Management Review, Forthcoming.

[2] Huang, X., A, Sawaya, and D. Zipser, "How China's Consumer Companies Managed through the COVID-19 Crisis: A Virtual Roundtable", McKinsey, 27 March 2020. [https://www.mckinsey.com/industries/retail/ourinsights/how-chinas-consumer-companies-managedthrough-the-covid-19-crisis-a-virtual-roundtable]

[3] Li, C. and F. Lalani, "The COVID-19 Pandemic Has Changed Education Forever, This is How", World Economic Forum, 29 Apr 2020.

[https://www.weforum.org/agenda/2020/04/coronaviruseducation-global-covid19-online-digital-learning/]

[4] Belzunegui-Eraso, A. and A. Erro-Garces, "Teleworking in the Context of the COVID-19 Crisis", Sustainability, 12(9), 3662, pp. 1-18.

[5] Chamola, V., V. Hassija, V. Gupta, and M. Guizani, "A Comprehensive Review of the COVID-19 Pandemic and the Role of IoT, Drones, AI, Blockchain, and 5G in Managing Its Impact”, IEEE Access, 2020, 8, pp. 90225 90265.

[6] Baig, A., B. Hall, P. Jenkins, E. Lamarre, and B. McCarthy, "The COVID-19 Recovery will be Digital: A Plan for the First 90 Days", McKinsey Digital.

[https://www.mckinsey.com/business-functions/mckinseydigital/our-insights/the-covid-19-recovery-will-bedigital-a-plan-for-the-first-90-days]

[7] Gasco-Hernandez, M., T.A. Pardo, and T. Nam, "Smart and Connected Cities and Communities Minitack (Introduction)", Proceedings of the $53^{\text {rd }}$ Hawaii International Conference on System Sciences, 2020.

[8]Lindskog, H., "Smart Communities Initiatives", Proceedings of the $3^{\text {rd }}$ IS One World Conference, 2004.

[9] Li, X., R. Lu, X. Liang, X. Shen, J. Chen, and X. Lin, "Smart Community: An Internet of Things Application", IEEE Communications Magazine, 2011, 49, 11, pp. 6875.

[10] Coe, A., G. Paquet, and J. Roy, "E-Governance and Smart Communities", Social Sciences Computer Review, 2001, 19(1), pp. 80-93.
[11] Benoit, G. and H. Kudo, "How are citizens involved in smart cities? Analyzing citizen participation in Japanese "Smart Communities"”, Information Polity, 2016, 21(1) pp. 61-76.

[12] Hopkins, E., F.T.C. Tan, C.M.L. Chan, C. Leong and A. Wright, "Digital Platform-Enabled Community Development: A Case Study of a Private-Public Partnership Sustainability Initiative", Proceedings of the $53^{\text {rd }}$ Hawaii International Conference on System Sciences, 2020.

[13] Cappellaro, F., R. Chiarini, C. Meloni, and C. Snels, "Smart Community Co-Creation: The Case of Centocello Project", International Journal of Sustainable Energy Planning and Management, 2019, 24, pp. 155-162.

[14] Bhattacharyya, S., S. Banerjee, I. Bose, and A. Kankanhalli, "Temporal Effects of Repeated Recognition and Lack of Recognition on Online Community Contributions", Journal of Management Information Systems, 2020, 37(2), pp. 536-562.

[15] Chan, C.M.L., M. Bhandar, L.B. Oh, and H.C. Chan, "Recognition and Participation in a Virtual Community", Proceedings of the $37^{\text {th }}$ Hawaii International Conference in Systems Sciences.

[16] Benjamin, V., H. Chen, and D. Zimbra, "Bridging the virtual and real: The relationship between web content, linkage, and geographical proximity of social movements", Journal of The Association for Information Science and Technology, 2014, 65(11), pp. 2210-2222.

[17] Nardi, B.A. and J. Harris, "Strangers and Friends: Collaborative Play in World of Warcraft", Proceedings of the 2006 ACM Conference on Computer Supported Cooperative Work, 2006.

[18] Grotherr, C., P. Vogel, and M. Semmann, "Multilevel Design for Smart Communities - The Case of Building a Local Online Neighborhood Social Community", Proceedings of the $53^{\text {rd }}$ Hawaii International Conference on System Sciences, 2020.

[19] Zhang, N., X. Zhao, and X. He, "Understanding the Relationships between Information Architectures and Business Models: An Empirical Study on the Success Configurations of Smart Communities", Government Information Quarterly, 2020, 37(2), 101439.

[20] Mandarano, L., M. Meenar, and C. Steins, "Building Social Capital in the Digital Age of Civic Engagement", Journal of Planning Literature, 2010, 25(2), 123-135.

[21] Murayama, A, "Institutional instruments for urban systems design-from the planner's perspective", In Yamagata Y., and Yang, P.P.J. (eds.), Urban Systems Design, 2020, pp. 409-427.

[22] Heeks, R. and A.V. Ospina, "Conceptualising the link between information systems and resilience: A developing country field study", Information Systems Journal, 2019, 29(1), pp. 70-96.

[23] United Nations Development Programme, "Towards Human Resilience", 2011.

[24] Maclean, K., M. Cuthill, and H. Ross, "Six Attributes of Social Resilience", Journal of Environmental Planning and Management, 2015, 57(1), pp. 144-156.

[25] Maguire, B., and P. Hagan, "Disasters and Communities: Understanding Social Resilience", Australian Journal of Emergency Management, 2007, 22(2), pp. 16-20. 
[26] Buikstra, E., H. Ross, C. King, P. Baker, D. Hegney, K. Mclachlan, and C. Rogers-Clark, "The Components of Resilience: Perception of an Australian Rural Community", Journal of Community Psychology. 2010, 28(8), pp. 976-991.

[27] Chatfield, A.T., H.J. Scholl, and U. Brajawidagda, “\#Sandy Tweets: Citizens' Co-Production of TimeCritical Information during an Unfolding Catastrophe", Proceedings of the $47^{\text {th }}$ Hawaii International Conference on System Sciences, 2014.

[28] Coleman, J. "Foundations of Social Theory", Harvard University Press, 1990.

[29] Putnam, R., "The Strange Disappearance of Civic America", Policy, 1996, Autumn, pp. 3-15.

[30] Dholakia, U.M. and R.P. Bagozzi, "Motivational Antecedents, Constituents, and Consequents of Virtual Community Identity", in Godar, S.H., and S.P. Ferris (eds.) Virtual and Collaborative Teams, IGI Global, 2003.

[31] Vaswani, K. "Coronavirus: The detectives racing to contain the virus in Singapore", BBC News, 19 March 2020.

[32] IMD, “Smart City Index 2019”, 2019. [https://www.imd.org/smart-city-observatory/smart-cityindex/]

[33] Strass, A. and J. Corbin, "Basics of Qualitative Research: Techniques and Procedures for Developing Grounded Theory", $2^{\text {nd }}$ ed., Sage, 1998.

[34] Langley, A. "Strategies for theorizing from process data", Academy of management Review, 1999, 24(4), pp. 691710 .

[35] Chan, C.M.L. and S.L. Pan, "User engagement in egovernment systems implementation: A comparative case study of two Singaporeans e-government initiatives", Journal of Strategic Information Systems, 17(2), pp. 124-139.

[36] Jones, L., "Coronavirus: What's Behind the Great Toilet Roll Grab?”, BBC News, 26 March 2020.

[37] Prior, R., "Why are we hoarding toilet paper? It may be your personality type", CNN, 12 June 2020.

[38] Koh, F., "About 40 instances of COVID-19 Fake News Debunked so far this year", The Straits Times, 5 May 2020.]

[39] Leong, D., "Commentary: Telegram, the powerful COVID-19 Choice of Communications by Many Governments", The Straits Times, 8 May 2020.

[40] Chong, C., "DBS Staff to befriend 1,000 seniors virtually to boost morale", The Straits Times, 15 June 2020.

[41] Lee, V., "Mother's Day under COVID-19: How Parenting changed during the pandemic", The Straits Times, 9 May 2020.

[42] Wong, K., "Families Celebrating Online This Mother's Day Due to Circuit Breaker Measures", ChannelNewsAsia, 10 May 2020.

[43] Lim, J., "Dutch Lilies and Kenyan Roses for Mother's Day", The Straits Times, 8 May 2020.

[44] Stewart, M., "No Visiting? No problem: Why a circuit breaker Hari Raya will still be special", CNA Lifestyle, 7 May 2020.
[45] Heng, M., "Malls, Shops Gear Up To Ensure Safety Measures and Crowd Control", The Straits Times, 19 June 2020.

[46] Chang, V., "Coronavirus: Canon Singapore Launches Self-Service Safe Entry Solution for Retail Stores and Offices", The Straits Times, 18 June 2020.

[47] Baharudin, H., "Coronavirus: Contact Tracing App Update Fixes Battery Drain in IPhones”, The Straits Times, 7 July 2020.

[48] Yip, W.Y., "Coronavirus: 10,000 seniors get first batch of TraceTogether Tokens", The Straits Times, 7 July 2020.

[49] Heng, M., "Coronavirus: Popular song Home sun across Singapore to thank front-line, migrant workers", The Straits Times, 25 April 2020.

[50] Kamil, A., "Unity in Crisis: Over 900 S'poreans form 'virtual choir' to sing Dick Lee's National Day theme song Home", Today, 14 April 2020.

[51] "Join the Entire Nation in Singing Home to Thank Healthcare, Migrant Workers", CNA Lifestyle, 23 April 2020.

[52] Ng, H.S., "Senior-Centric Activities by Government Agencies to be Suspended as Part of Additional COVID19 Measures: MOH", ChannelNewAsia, 11 March 2020.

[53] Come 'N Live

[https://www.zaobao.com.sg/keywords/come-n-live-atzaobaosg]

[54] Chong, C., "DBS Staff to Befriend 1,000 Seniors Virtually to Boost Morale", The Straits Times, 15 June 2020.

[55] Wong. L., "More affordable mobile data plans for lowincome seniors", The Straits Times, 30 June 2020.

[56] Yeoh, G., "46 SG Digital Community Hubs to be Launched Islandwide by end August", ChannelNewsAsia, 7 July 2020.

[57] Tham. Y-C., "More Help for Seniors and Hawkers to Adopt Digital Technology", The Straits Times, 13 June 2020.

[58] Guan, C. and C.M.L. Chan, "Commentary: Has COVID19 made e-Commerce and Online Shopping the New Normal", ChannelNewsAsia, 7 April 2020.

[59] Tan, S-A., "Companies to Maintain Status Quo on Working From Home for Now", The Straits Times, 17 June 2020.

[60] Tang, S.K., "Tekka Market Stalls Turn to Live-Streaming to Sell Fresh Produce, As People Stay Home Amid COVID19.", ChannelNewsAsia, 5 May 2020.

[61] Tang, S.K., "COVID-19 Drives More Wet Market Stalls Online, But Will They Be Here to Stay?", ChannelNewsAsia, 15 May 2020.

[62] Ho, G., "Digital and Social Resilience Key to Emerging Stronger From COVID-19 Pandemic: Indranee Rajah", The Straits Times, 11 June 2020.

[63] Tham, Y-C., "More Help for Seniors and Hawkers to Adopt Digital Technology", The Straits Times, 13 June 2020. [64] D'Silva, J., "Commentary: NDP a uniquely Singapore Phenomenon", ChannelNewsAsia, 20 June 2020.

[65] Kaur, A., "National Day Parade Can Be Restructured to Make it More Intimate, and Not Postponed or Cancelled: Dick Lee", The Straits Times, 15 March 2020. 
[66] Lim, M.Z., "NDP 2020" Focus on Celebrating at Home, Many Segments Moved to the Heartlands and Smaller-Scale Evening Show", The Straits Times, 20 May 2020.

[67] Zheng, Z., "Close to 50,000 people want to opt-out from receiving NDP 2020 fun pack", Mothership, 22 May 2020.

[68] Zhang, J., "S'pore Residents Concerned that NDP funpacks for 1.2 million households will be wasteful", Mothership, 21 May 2020.

[69] Tan, A., "S'poreans Don't Need the NDP Funpack. We Survived Just Fine Before It was Introduced in 1991", Mothership, 30 May 2020.

[70] Wong, C., "NDP Organisers Exploring Opt-Out Option for Funpacks, Says MP; Govt Seeks Feedback on Issue", The Straits Times, 25 May 2010.

[71] "On Facebook: NDP Funpacks", The Straits Times, 30 May 2020.

[72] Wong, C., "Parliament: NDP Exco to Produce Packs for $80 \%$ of Households; Those Who Want One Can Collect Them From CCs", The Straits Times, 5 June 2020.
[73] Tim, Y., S.L. Pan, P. Ractham, and L. Kaewkitipong, "Digitally Enabled Disaster Response: The Emergence of Social Media as Boundary Objects in a Flooding Disaster", Information Systems Journal, 2017, 27(2), pp. 197-232.

[74] Reuter, C., and T. Spielhofer, "Towards Social Resilience: A quantitative and Qualitative Survey on Citizens' Perception of Social Media in Emergencies in Europe", Technology Forecasting \& Social Change, 2017, 121, pp. 168180.

[75] Young, J.C., "Rural Digital Geographies and New Landscape of Social Resilience", Journal of Rural Studies, 2019, 70(1), pp. 66-74.

\section{Acknowledgement}

Part of this research is supported by the Fujian Natural Science Foundation Project 'Research on Dynamic Evaluation of Regional Innovation Ecosystem in Innovation 3.0 Environment' (Grant No. 2018J01647). 